\title{
Investigating Lexical Diversity of Children's Oral Narratives: A Case Study of L1 Speaking
}

\author{
Famala Eka Sanhadi Rahayu, ${ }^{1}$ Aries Utomo, ${ }^{2 *}$ Ririn Setyowati ${ }^{3}$ \\ 1,2,3 Department of English Literature, Faculty of Cultural Sciences, Universitas \\ Mulawarman, Samarinda - Indonesia \\ ${ }^{*}$ Corresponding Author \\ Email: aries.utomo91@fib.unmul.ac.id \\ DOI: 10.18326/rgt.v13i2.371-388
}

Submission Track:

Received: 26-08-2020

Final Revision: 14-11-2020

Available Online: 01-12-2020

Copyright (C) 2020 Famala Eka Sanhadi Rahayu, Aries Utomo, Ririn Setyowati

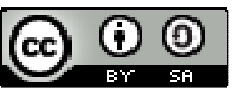

This work is licensed under a Creative Commons Attribution-ShareAlike 4.0

International License.

\begin{abstract}
Lexical diversity is one of the language tools used to measure varied words or vocabulary produced by learners both spoken and written. This research aims to investigate lexical diversity of children narratives produced by children orally. The research design of this research is a case study supported by quantitative data. Meanwhile, the subjects of this research are seven children around 6-9 years old. Regarding data collection, the researchers employed a narrative storytelling based on a picture drawn by the subjects. Analysing data, TTR (Type-Token -Ratio) was used to measure the lexical diversity gained from the subjects by supporting relevant theories to explain the phenomena. Based on the findings, it is has been found that (1) older children have higher lexical diversity than the younger ones, (2) younger children produced higher lexical frequency (word tokens) than the older ones, and (3) individual variations showed anomalies of the result in which older children were expected to have higher lexical frequency but the result showed the reverse English.
\end{abstract}

Keywords: lexical diversity; children; oral narratives; case study 


\section{INTRODUCTION}

Language acquisition is one of topics discussed in psycholinguistics along with language production and language comprehension (Maftoon \& Shakouri, 2012). In linguistics studies, researchers have shown more interests in second language acquisition, which placed the first language acquisition aside. However, first language acquisition still correlates with how second language acquisition is elaborated. Examining first language acquisition with other theories from psycholinguistics, for instance, language productivity is still uncommon, but interesting. Therefore, the current study has given rise to the explanation about children's language production in their first language.

The study of children's language acquisition is a field of study, which has already been interesting for linguists over a hundred years. The second characteristic of child language is that it has accumulated a great amount of information about children's linguistic behaviour over years. For instance, children's language studies have provided a multitude of data, such as their first words, the kinds of words children utter, and the kinds of errors they make. It shows facts about what actually happens in children's language (Ingram, 1989).

The field of child language acquisition is one that has gone through several changes over the years in both methods and theoretical orientation used. In advance, the theory of acquisition has two distinct components; they are competence factors and performance factors. According to Chomsky (as cited in Ridge, 2013), competence consists of the mental representations of linguistic rules that constitute the speaker-hearer's internal grammar. Performance consists of the use of this grammar in the comprehension and production of language. Competence factors deal with principles related to the construction of the grammar or in another word. It focuses on the nature of the child's rule system. On the other hand, performance factors focus on the psychological processes the child uses in learning the language. Therefore, performance factors dig deeper into the child's comprehension and production of language (Ingram, 1989)

In competence factors, there are two possible principles that have been proposed, one dealing with acquisition of morphology and the other is the 
acquisition of syntax. Being gained an example of English language context, in which native English children have a tendency to overgeneralize the morphological inflectional suffixes in English to irregular forms, saying things like 'mans' and 'breaked'. Dresher (1981) has proposed a principle to account for these overgeneralizations as part of a detailed analysis of the learnability of old English morphology. He also explains that consistency against the highly valued rules must be adopted by a learner consistently and is called as generalization principle (Dresher, 1981). Relating to this research, it aims to measure children's ability to produce words whether consistently or not.

In another point, generalization principle is not sufficient to account for the acquisition of morphological endings. To account for this, another principle is needed which is elsewhere. Ingram (1989) has called the lexical principle, which is the principle that learns individual paradigmatic alternations as separate lexical items. This principle claims the child acquires paradigmatic variants like 'book, books', 'cow, cows' as separate words and later realizes that those words are same words with different morpheme '-s'. Having these two theories are not enough to explain the condition under which the one yields to the other, therefore it is rational to take the principle into account.

The child could conclude that there are two forms of the plural for 'foot', these being 'foots' and 'feet'. Wexler and Culicover (1980) who have led the research into principles of language acquisition, propose the uniqueness principle to make this last step. The principle, in its most general form, will tell the child to select only one of the above forms, the one that is used in the child's linguistic environment. As with the other principles, we will leave its exact formulation open. These three principles are: the lexical principle, the generalization principle, and the uniqueness principle. Those are kinds of three principles that will be part of the theory of acquisition that attempts to explain morphological acquisition.

It is not surprising to realize that children can vary greatly in their language use. This individual variation among children is a feature that is emphasized by some and minimized by others. Ingram (1989) proposed three sources for variation between children, which are performance variation, environmental variation, and linguistic variation. Performance variation 
determines individual capacities of abilities of the child that lead to preferences for particular linguistic subsystems. On the other hand, it relates to environmental effects, which determine the richness of lexicon acquired by the children. The last is linguistic variation, which is due to the range of structural possibilities allowed by Universal Grammar.

Children have different ways to learn their first and second language acquisition including the development of their lexical ability. They may be given the same things to say, but they have a different interpretation in saying it, by using different vocabularies. It can be caused by the influence of social condition around them. The knowledge acquired is largely of an unconscious sort (Gass \& Selinker, 2008). In acquiring a language, a learner learns the language through many ways. In countries such as England and France, many children are socialized in a variety of the standard language, and it seems clear what their first language is. But the majority of the world population is multilingual, and for many people there is no a clear-cut to constitutes their first, second or third language (de Bot, 2004). In addition, Krashen \& Terrell (1983) define that 'acquisition' as the product of a 'subconscious' process is very similar to the one children use in learning their first language, and learning as the product of formal teaching, which results in 'conscious' knowledge about the language, but the distinction cannot be as simple as that.

In another definition, language acquisition is also studied for second language and also known as second language acquisition. Siegel (2010) defines second language acquisition as the study of second language acquisition (often abbreviated as SLA), which examines how people who already speak a first language (L1) subsequently acquire a second or additional language (L2). Saville-Troike (2012) argues that second language acquisition (SLA) refers to both the study of individual and groups who are learning a language subsequent to learning their first one as young children, and the process of learning that language.

In the development of acquiring a language, lexical complexity is known as how someone chooses words in orally or written language. Lu (2012) explains that lexical complexity (LC) talks about the writer's ability to communicate effectively in written form. LC is presented in second language acquisition 
having three kinds of it, namely: (1) lexical density, (2) diversity/variability, and (3) sophistication/rareness.

Lexical diversity variables have been applied to many areas of linguistic investigation. These include first and second language classrooms (Foster \& Tavakoli, 2009), assessment of writing in second language ability (Akbari, 2017; Arya et al., 2011; González, 2017; Gregori-Signes \& Clavel-Arroitia, 2015; Juanggo, 2018; Kalantari \& Gholami, 2017; Koizumi \& In'nami, 2012), assessment of speaking and writing (Yu, 2010), and language impairment (Silverman \& Ratner, 2002; Stokes \& Fletcher, 2000; Watkins et al., 1995).

According to Malvern et al. (2004), lexical variation means the same as lexical diversity and the range of vocabulary and avoidance of repetition and is measured by comparing the number of different words with the total number of words written, traditionally using the type-token ratio (TTR). In this article, lexical diversity is chosen and investigated by the researchers. Lexical diversity/variation (LV) is a measure to assess how varied words or vocabulary are produced by learners in a text. In other words, in the production of language, the speaker or the writer has to use a large number of different words with no or little repetition in their utterances and writings to count as highly lexically diverse (Juanggo, 2018). Lexical diversity is viewed as referring to the range of vocabulary in a piece of writing and includes only the breadth of vocabulary knowledge (Malvern et al., 2004). Wang \& Wang (2014) also add that quantifying the level of lexical diversity involves identifying how often words are used in a text. Based on the explanations above, it can be concluded that lexical diversity is a vocabulary mastery having by someone, which is expressed in the form of writing. Besides that, it draws how often words are used by someone in a text. In measuring the lexical diversity, the TTR (TypeToken Ratio) is commonly used in various investigations. To know the variation of different words, it was employed in the case of type and the total number of words in a text as tokens.

Recent studies have shown a big interest in investigating the lexical diversity in L2 context (Arya et al., 2011; Carlisle \& Fleming, 2003; GregoriSignes \& Clavel-Arroitia, 2015) and EFL context (Juanggo, 2018) but none of them has studied lexical diversity in L1 context. Most of the previous research 
gain data from written text (Akbari, 2017; Arya et al., 2011; González, 2017; Gregori-Signes \& Clavel-Arroitia, 2015; Juanggo, 2018; Kalantari \& Gholami, 2017; Koizumi \& In'nami, 2012), the students' understanding on reading (Carlisle \& Fleming, 2003), and children's speaking impairment (Silverman \& Ratner, 2002; Stokes \& Fletcher, 2000; Watkins et al., 1995). Therefore, this study attempts to see the lexical complexity from different point of view that is from oral presentation through the narrative story. Not only do context and source of data differ between the present study and the previous study. The present researchers then realized that L1 lexical diversity is also important to depict the children's language acquisition, which can be a factor influencing how they acquire their $\mathrm{L} 2$. Therefore, this research takes place in $\mathrm{L} 1$ context.

This article is focused on (1) the lexical diversity at the critical period children (6-9 years old) and (2) how the children produce lexical diversity using TTR measurement through their oral language in telling pictures, which was drawn by themselves.

\section{RESEARCH METHOD}

The research design used was a case study supported by quantitative data. Yin (2012) explains that case study is used in many situations to contribute to knowledge of individual, group, organizational, social, political, and related phenomena. The interviewed-based qualitative approach and corpus study approach are employed to find the children's lexical diversity gained from narrative story they made. The interview-based approach are used to gain data (lexicon produced by the children), which were transcribed in to written text and considered as corpus data of this study.

The subjects of this research were 7 children aged from 6-9-year-old who consider passing the golden age (until 5 years old) and are still in critical period (3-9 years old). Those subjects were chosen regardless of their social background and education, which can be the factors affecting their lexical diversity. So, the researchers randomly took seven children to avoid bias in looking for particular answers. Analyzing the data, the oral narratives were conducted twice, in which the children were requested to draw a picture and tell the story about their pictures in the first presentation. In the second chance, 
the children were asked to tell the story based on a sequence of pictures to reveal their lexical diversity. The oral narratives were recorded and transcribed to help the researchers analyze the data. The researchers also considered taking the longest oral narrative from the two data obtained. To calculate the lexical diversity, the researcher employed TTR (Types-Token-Ratio), which could depict how varied the children's words are. TTR describes the ratio between the number of different words (types) and the total number of words (tokens) (Malvern, D., Richards, B., Chipere, N. \& Puran, 2004). For instance, there are 14 tokens but 12 types in the following sentence: I Mary goes to Edinburg next week, and she intends going to Washington next month. The two occurrences of to and next each belong to the same type. The type-token-ratio is calculated and reported as a percentage using the following formula:

$$
\mathrm{TTR}=\frac{\text { the number of different words (types) }}{\text { the numbar of total words (tokens) }}
$$

However, a significant weakness of the TTR method when it is used to compare texts is the sensitivity of the measure to variability in text length (Nation \& Webb, 2011). As a text gets longer, there are fewer chances for new types to appear, because a high proportion of the frequent types have already appeared. However, TTR is still used for comparing text production (Johansson, 2009). In this study, the researchers assume that text production will not be too long since the participants are children; therefore, the use of TTR in this study is acceptable.

\section{FINDINGS \& DISCUSSION}

Lexical diversity is a vocabulary variation produced by the participants, which is measured by dividing the number of word type by the word tokens. The word token itself is also called lexical frequency, which depicts how many words are produced in a text both spoken or written. According to the definition, there are two main findings in this result of study: 1) the older children have higher lexical diversity than the younger ones, and 2) the younger ones produce higher lexical frequency in this study reflected by the number of tokens produced by the participants, than the younger ones. 
Based on the findings, the researchers identify and classify data found on Table 1. As previously mentioned, lexical diversity depicts how varied words or vocabulary are produced by the children. In other words, in the production of language, the children have to use a large number of different words with no or little repetition in their utterance and writing to count as highly lexically diverse (Juanggo, 2018). According to Table 1, lexical diversity is degraded from the older children to the younger children, which means older children have a higher lexical diversity than the younger ones. However, an anomaly happens with $\mathrm{P} 4$, who shows her lexical diversity as the lowest among them.

Lexical diversity, as mentioned previously, strongly correlates with the number of word types and tokens which the participants produce. It means the participants who produce more word tokens (as in P6 and P7) but have same number of word types were naturally low in lexical diversity. It can be seen from the table which shows that they produce more than one hundred words which three times or more higher than what other older participants produce. A similar number of word types for all participants have different in producing word tokens that lead to this result to take lexical frequency or word tokens into accounts.

Table 1. Data of Lexical Diversity gained from Participants

\begin{tabular}{clll}
\hline No. & Subjects & Age & Lexical Diversity \\
\hline 1 & P1 (Female) & 9 years old & 0,62771 \\
2 & P2 (Female) & 9 years old & 0,82674 \\
3 & P3 (Male) & 9 years old & 0,79487 \\
4 & P4 (Female) & 9 years old & 0,35 \\
5 & P5 (Female) & 8 years old & 0,584415 \\
6 & P6 (Female) & 7 years old & 0,54845 \\
7 & P7 (Male) & 6 years old & 0,36322 \\
\hline
\end{tabular}

Table 2. Lexical Frequency

\begin{tabular}{clll}
\hline No. & Subjects & Age & Token \\
\hline 1 & P1 (Female) & 9 years old & 58 \\
2 & P2 (Female) & 9 years old & 80 \\
3 & P3 (Male) & 9 years old & 39 \\
4 & P4 (Female) & 9 years old & 55 \\
5 & P5 (Female) & 8 years old & 69 \\
6 & P6 (Female) & 7 years old & 301 \\
7 & P7 (Male) & 6 years old & 223 \\
\hline
\end{tabular}


Lexical frequency or word token is the number of word occurences in the participants' narrative texts regardless of their types. It means that lexical frequency counts a repetitive occurence into different count. This study reports that younger children (P6 and P7) produce higher lexical frequency than the older ones. The table above shows that P6 produce 301 word tokens and P7 produce 223 word tokens. Meanwhile, P1-P5 produce 39-80 word tokens in which the value is three times less than what P6 and P7 produce. In addition, P3, who is included in older children ( 9 years old), showed the fewest word tokens among the participants by producing 39 word tokens in his narrative. This result is different with the researchers's pre-assumption that older children produce higher lexical frequency than the younger ones.

The gap between the researchers' pre-assumption and the result of the study can be explained by the existence of individual variation influencing the children in acquiring their first language. In spite of generalization principle and lexical principle, there is a uniqueness principle, which needs to be taken into account, which explains the individual variation that may cause the exceptional result of the study (Ingram, 1989). Individual variation covers three variations: performance variation, environmental variation and linguistic variation. Children are varied in terms of their performance. Each child has his or her own tendency to be a talkative or not. Children who are genetically talkative naturally talk more and produce more lexical frequency than those who are not, while environmental variation, on the other hand, relates to environmental effects, which determine the richness of lexicon acquired by the children. Environmental variation closely deals with the information inputs that the children get from their surrounding. This variation is strongly affected by the children's hobby, family preference, and children social life. Children who like reading, watching TV, are talking with others are more active linguistically. It means that they are likely to produce more words than the average children. This aspect will surely affect their lexical frequency although it sometimes does not go in line with the lexical diversity. It is due to lexical frequency matters on how many words are produced regardless of the types, so it can be possible that children produce repeated words. The last is linguistic variation, which is related to the linguistic system embedded in the participants. The individual 
variations are the best theory to explain the phenomena depicted in the result of the study. Therefore, the researchers present the finding by highlighting each participant's individual variation as in the following paragraph.

P1 is a 9-year-old girl and a fourth grade student in one state elementary school located in North Samarinda. Her hobby is drawing flowers. All words that she produced are influenced by flowers. While the researcher took the data, the participant showed her interests in telling a story related to flowers and most of the words are visually mentioned in the picture. She could make a difference by several word colours related to the flowers drawn by her, such as: merah, kuning, hijau, putih, and kuning including her reasons to choose those colours.

P2 is a 9-year-old girl and a fourth grade student in one private Islamic elementary school located in North Samarinda. Her hobby is travelling. All the words she produced are influenced by the hobby. While the researcher took the data, the participant showed her interests in telling a story related to travelling in a village where many children play with her. Most of the words are visually mentioned in the picture, but there are no any special words found from P2. She just employed usual words, which are produced in her age generally.

P3 is a nine-year-old boy who has his own imagination. He spends his day alone at home when his mother goes to work and never has enough time to interact with his parents or friends. It made him feel a bit shy when someone (the researcher) asked him to draw a picture and describe its story. He is actually a big fan of Ultraman movie, which is expected to appear in his story but unfortunately he did not say anything about it. It was because he thought it was formal-interview, which required him to act unnaturally. In the first attempt, he mentioned an unusual word such as handphone to be associated with the scenery that he drew. In his drawing, he told about his family with his own activity which means that it might be a thing they did regularly like ayah merokok and mama memegang $\mathrm{hp}$. Instead of talking about something he liked such as Ultraman or other boyish figures, he prefered to talk about his daily life. In the second occasion, he told about Ultraman and felt interested in telling the story but as soon as the researcher started the recording he ended his story. His social withdrawal deterred his show inevitably. 
P4 is a 9-year-old girl and a fourth grade student in one state elementary school located in North Samarinda. Her hobby is drawing mountains. All the words she produced are influenced by the mountains. While the researcher took the data, the participant showed her interest in telling a story relating to the mountains and most of the words are visually mentioned in the picture. There are several special words used by her, such as: petak. It indicates that she understands the word.

P5 is an 8-year-old girl in the third grade of elementary school in Samarinda. She has a picture about a house. Her concept of a house is that it has a fence, tree, grass around it, but in a short explanation. She has explained that she could only explain briefly because she drew a small picture.

P6 is a 7-year-old girl and she is now in second grade of elementary school in Samarinda. She is an expressive girl who likes singing, dancing, and telling stories. She drew and told about a zoo with some animals stated in her drawing namely a giraffe and a tiger. There was an animal that she did not draw in her picture but she told about it, it is an elephant. She said that the elephant is a wild and dangerous animal like the tiger. From her story about elephants, it shows that this girl is imaginative because she could tell something that did not exist in her picture because this animal has a similarity with the tiger that she explained. The similarities between the tiger and the elephant are wild and dangerous especially for the people around them. Therefore, that is the reason why she drew some fences to protect people from those wild animals. During the story, P6 often involved the researcher to build communication by uttering the interrogative statement 'Terus kita lanjutkan dengan binatang-binatang yang lain, Mau ndak?'. Some interesting words that she produced were Zoo, buas, pagar and hati-hati. She understood well about those correlated words by assuming that by playing at the zoo, we must be careful and always take care of ourselves because there are some wild animals in that place.

P7 is a six-year-old boy who just finished kindergarten. His hobby is watching Disney Junior channel all day long so all the words he produced are influenced by the movie he watched. He often watched almost all cartoons showing in the channel even if the shows are repetitive. Therefore, he almost remembered all the plots and even the dialogue, which influenced his daily 
vocabulary. It also happens in the time when the researcher took the data. He first drew a laptop and showing that the laptop is loading by drawing a loading icon in the laptop. Instead of drawing a full-paper drawing, he drew a series of pictures and telling the series of story according to the picture. In the first attempt, he mentioned laptop and loading and telling a story about an invention but he struggled to describe it. In another attempt, he told a story without drawing it because he was not into drawing. When the researcher collected the data, the participant showed his interest in a fiction story so most of the words are usually mentioned in a fiction story. The phrases like tongkat kegelapan, tongkat cahaya, dahsyat are mentioned in the data. He interestingly told the story but often repeated his words since he showed symptoms of mild stuttering. However, his word production was inevitably amazing.

\section{Discussion}

According to the findings above, the researchers found that older children tend to have higher lexical diversity than the younger ones except for the participant number 4 , who produced the lowest lexical diversity among them. However, the younger children (P6 and P7) produced more word tokens than the older children. They showed about four to eight times more word tokens than the older children, which gives a reason why their lexical diversity is half as low as the older ones'. In a fewer words story, the children will have a bigger chance to avoid repetitive words since they only speak about two or three sentences. On the other hand, the children with more words in their story will find that repetitive words are inevitable. They produced more than twenty sentences so the chances to repeat the words are higher. Gregori-Signes \& Clavel-Arroitia (2015) explain that a high type/token ratio indicates how well a learner expresses himself with his own vocabulary and not the types of words.

In this research, the researchers explain the phenomena created by the gap between the researchers' pre-assumption and the result of the study by using uniqueness principles, so called individual variations (Ingram, 1989). Three variations are covered in individual variations: performance variations, environmental variations, and linguistic variations are explained as factors that determine the number of lexical diversity and lexical frequency in the 
participants' oral narratives. However, the researchers only investigate the explanation of individual variation based on performance and environmental variations since to investigate linguistic variation, a complex and advance treatment needs to be done to find out the linguistic system used in each participant.

In terms of performance variations, some children who are silent and others, talkative. In this study, P6 and P7 are two examples of talkative children; they could produce more words. On the other hand, P4 is a silent child, which is confirmed by her mother, who said the daughter does not talk much. She may have many things she wants to say about her drawing but it turns out it is kept inside as what silent children do.

On the other hand, environmental variations also influence the children's lexical diversity and frequency. Environmental variations cover several aspects such as the children's hobby, family condition, and children's social life. Take P6 and P7 as instances, both of the children have many relatives who talk with them a lot, which influences their vocabulary input. Besides, those who always talk with them are adults. Adults usually have difficult words for some children to understand but if they eventually understand it, it surely enriches their vocabulary. Watching movies is also a vocabulary source especially for $\mathrm{P} 7$, who watched a translated English movie, which provides sophisticated words for the children. The different thing happens for P3, who always at home if he does not go to school. Living with his working parents and no other relatives make his chance to meet people is only at school so he does not have more input to acquire more words like what experience by P6 and P7. It reflects the realization that some words may be useful to some learners even if they are not generally frequent in the language, depending on the specific needs that learners may have.

Beside individual variations, the researchers found that the situation when administering the study has influenced the result of the study. It is an unfamiliar situation, which has mentioned that in case of $\mathrm{P} 3$, he felt uncomfortable when the researcher asked him to draw a picture and to tell the story. He presented himself like he is at school so what he did is more formal than what the researcher expected. A similar situation happened with other children, but for 
P6 and P7 who are accustomed to talking with adults do not find any difficulties talking with the researchers and did what the researchers asked to do. The researchers indicate that the participants gained problems in speaking. Boonkit (2010) explains through principles of speaking, namely: to give learners practice both fluency and accuracy, and provide opportunities for them to talk using group work or pair work in order to motivate their speaking.

\section{CONCLUSION}

From the findings and discussion, the researchers have come to the conclusion that can be stated by the researchers related to lexical diversity of children oral narratives, which goes as follows:

Older children tend to have higher lexical diversity than the younger ones do. However, there is a case where a participant showed lower lexical diversity than the younger children did. Younger participants in this study showed higher lexical frequency than the older participants did. However, this phenomenon is closely related to individual variations that distinguish each participant, which cannot be generalized. Some students are silent and others are talkative. Environmental variation is also a matter in word production since what they have in daily life will influence them much. An unfamiliar situation also becomes a factor affecting children when they produce words.[rgt]

\section{REFERENCES}

Akbari, N. (2017). Lexical diversity and the use of academic and lower frequency words in the academic writing of EFL students. Australian Review of Applied Linguistics, 40(1), 3-18. https://doi.org/10.1075/aral.40.1.02akb

Arya, D. J., Hiebert, E. H., \& Pearson, P. D. (2011). The effects of syntactic and lexical complexity on the comprehension of elementary science texts. 4(1), 107-125.

Boonkit, K. (2010). Enhancing the development of speaking skills for non-native speakers of English. Procedia - Social and Behavioral Sciences. https://doi.org/10.1016/j.sbspro.2010.03.191 
Carlisle, J. F., \& Fleming, J. (2003). Lexical Processing of Morphologically Complex Words in the Elementary Years. Scientific Studies of Reading. https://doi.org/10.1207/s1532799xssr0703_3

de Bot, K (2004). The multilingual lexicon: Modelling selection and control. International Journal of Multilingualism. https://doi.org/10.1080/ 14790710408668176

Foster, P., \& Tavakoli, P. (2009). Native speakers and task performance: Comparing effects on complexity, fluency, and lexical diversity. Language Learning, 59(4), 866-896. https://doi.org/10.1111/j.14679922.2009.00528x

Gass, S. M., \& Selinker, L. (2008). The role of the native language: an historical overview. In Second language acquisition: an introductory course.

González, M. C. (2017). The Contribution of Lexical Diversity to College-Level Writing. TESOL Journal, 8(4), 899-919. https://doi.org/10.1002/tesj.342

Gregori-Signes, C., \& Clavel-Arroitia, B. (2015). Analysing Lexical Density and Lexical Diversity in University Students' Written Discourse. Procedia - Social and Behavioral Sciences. https://doi.org/10.1016/j.sbspro.2015.07.477

Ingram, D. (1989). First Language Acquisition: Method, Description, and Explanation. 1-572.https://doi.org/10.1177/002383099003300205

Johansson, V. (2009). Lexical diversity and lexical density in speech and writing: a developmental perspective. Working Papers in Linguistics. https://doi.org/ 10.7820/vli.v01.1.koizumi

Juanggo, W. (2018). Investigating lexical diversity and lexical sophistication of productive vocabulary in the written discourse of Indonesian EFL learners. Indonesian Journal of Applied Linguistics. https://doi.org/10.17509/ ijal.v8i1.11462

Kalantari, R., \& Gholami, J. (2017). Lexical complexity development from dynamic systems theory perspective: Lexical density, diversity, and sophistication. International Journal of Instruction, 10(4), 1-18. https://doi.org/10.12973/ iji.2017.1041a

Koizumi, R., \& In'nami, Y. (2012). Withdrawal notice to: Effects of text length on lexical diversity measures: Using short texts with less than 200 tokens. System, 40(4), R1. https://doi.org/10.1016/j.system.2012.11.001

Krashen, S., \& Terrell, T. (1983). the_Natural_Approach.Pdf. In Stanford Education. 
Lu, X. (2012). The Relationship of Lexical Richness to the Quality of ESL Learners' Oral Narratives. The Modern Language Journal, 96(2), 190-208. https://doi.org/10.1111/j.1540-4781.2011.01232.x

Maftoon, P., \& Shakouri, N. (2012). Psycholinguistic Approach to Second Language Acquisition. The International Journal of Language Learning and Applied Linguistics World.

Malvern, D., Richards, B., Chipere, N. \& Puran, P. (2004). Lexical diversity and language development: quatitative and assessment.

Malvern, D., Richards, B., Chipere, N., \& Durán, P. (2004). Lexical Diversity and Language Development. In Lexical Diversity and Language Development. https://doi.org/10.1057/9780230511804

Ridge, E. (2013). R. Ellis: The study of second language acquisition. In Per Linguam (Vol. 10, Issue 1). https://doi.org/10.5785/10-1-248

Saville-Troike, M. (2012). Introducing Second Language Acquisition. In Introducing Second Language Acquisition. https://doi.org/10.1017/ cbo9780511808838.002

Siegel, J. (2010). Second dialect acquisition. In Second Dialect Acquisition. https://doi.org/10.1017/CB09780511777820

Silverman, S., \& Ratner, N. B. (2002). Measuring lexical diversity in children who stutter: Application of vocd. Journal of Fluency Disorders, 27(4), 289-304. https://doi.org/10.1016/S0094-730X(02)00162-6

Stokes, S. F., \& Fletcher, P. (2000). Lexical diversity and productivity in Cantonesespeaking children with specific language impairment. International Journal of Language and Communication Disorders, 35(4), 527-541. https://doi.org/ 10.1080/136828200750001278

Wang, X., \& Wang, X (2014). The relationship between lexical diversity and EFL writing proficiency. University of Sydney Papers in TESOL.

Watkins, R. V., Kelly, D. J., Harbers, H. M., \& Hollis, W. (1995). Measuring children's lexical diversity: Differentiating typical and impaired language learners. Journal of Speech and Hearing Research, 38(6), 1349-1355. https://doi.org/ 10.1044/jshr.3806.1349

Wexler, K., \& Culicover, P. W. (1980). Formal principles of language acquisition. MIT Press (MA). 
Investigating Lexical Diversity of Children's Oral Narratives ....

Yin, R. K. (2012). Case study methods. In Handbook of Complementary Methods in Education Research. https://doi.org/10.4324/9780203874769-11

Yu, G. (2010). Lexical diversity in writing and speaking task performances. Applied Linguistics, 31(2), 236-259. https://doi.org/10.1093/applin/amp024 
This page intentionally left blank. 